This item was submitted to Loughborough's Research Repository by the author.

Items in Figshare are protected by copyright, with all rights reserved, unless otherwise indicated.

\title{
Electrolyte supplementation during severe energy restriction increases exercise capacity in the heat
}

PLEASE CITE THE PUBLISHED VERSION

http://dx.doi.org/10.1007/s00421-015-3254-1

\section{PUBLISHER}

(C) Springer

VERSION

AM (Accepted Manuscript)

\section{PUBLISHER STATEMENT}

This work is made available according to the conditions of the Creative Commons Attribution-NonCommercialNoDerivatives 4.0 International (CC BY-NC-ND 4.0) licence. Full details of this licence are available at: https://creativecommons.org/licenses/by-nc-nd/4.0/

\section{LICENCE}

CC BY-NC-ND 4.0

\section{REPOSITORY RECORD}

James, Lewis J., Stephen A. Mears, and Susan M. Shirreffs. 2019. "Electrolyte Supplementation During Severe Energy Restriction Increases Exercise Capacity in the Heat". figshare. https://hdl.handle.net/2134/20828. 


\section{Electrolyte supplementation during severe energy restriction increases exercise}

\section{capacity in the heat}

Lewis J. James*, Stephen A. Mears and Susan M. Shirreffs

School of Sport, Exercise and Health Sciences, Loughborough University,

Loughborough, UK

*Corresponding author: L. J. James

E-mail: L.James@Lboro.ac.uk

Tel: +44 (0) 1509226305

Fax: +44 (0) 1509226301

Running head: Energy restriction and exercise capacity 


\section{Abstract}

PURPOSE: This study examined the effects of sodium chloride and potassium chloride supplementation during $48 \mathrm{~h}$ severe energy restriction on exercise capacity in the heat.

METHODS: Nine males completed three 48 h trials: adequate energy intake (100\% requirement), adequate electrolyte intake (CON); restricted energy intake (33\% requirement), adequate electrolyte intake (ER-E); and restricted energy intake (33\% requirement), restricted electrolyte intake (ER-P). At 48 h, cycling exercise capacity at $60 \% \dot{V} \mathrm{O}_{2}$ peak was determined in the heat $\left(35.2^{\circ} \mathrm{C} ; 61.5 \%\right.$ relative humidity).

RESULTS: Body mass loss during the $48 \mathrm{~h}$ was greater during ER-P (2.16 (0.36) kg) than ER-E (1.43 (0.47) kg; $P<0.01)$ and CON (0.39 (0.68) kg; $P<0.001)$, as well as greater during ER-E than CON $(P<0.01)$. Plasma volume decreased during ER-P $(P<0.001)$, but not ER-E or CON. Exercise capacity was greater during CON (73.6 (13.5) min) and ER-E (67.0 (17.2) min) than ER-P (56.5 (13.1) min; $P<0.01)$, but was not different between CON and ER-E ( $P=0.237)$. Heart rate during exercise, was lower during CON and ER-E than ER-P $(P<0.05)$.

CONCLUSIONS: These results demonstrate that supplementation of sodium chloride and potassium chloride during energy restriction attenuated the reduction in exercise capacity that occurred with energy restriction alone. Supplementation maintained plasma volume at pre-trial levels and consequently prevented the increased heart rate observed with energy restriction alone. These results suggest that water and electrolyte imbalances associated with dietary energy and electrolyte restriction might contribute to reduced exercise capacity in the heat.

Key words: Hydration; Fluid Balance; Dehydration; Hypohydration; Fasting

\section{List of abbreviations:}

ER: Energy restriction

RPE: Rating of perceived exertion

$\mathrm{T}_{\text {rec }}$ : Rectal temperature

$\mathrm{T}_{\mathrm{sk}}$ : Skin temperature

TC: Thermal comfort 
CON: Control trial

ER-E: Energy restriction with electrolyte supplementation trial

ER-P: Energy restriction with placebo supplementation trial 


\section{Introduction}

Severe energy restriction (ER) might be encountered in a number of athletic, occupational and everyday settings. For example, military personnel in the field, as well as both athletes and dieters aiming to reduce body mass might all encounter short term periods of severely restricted energy intake.

Military personnel, undergoing military training or sustained operations where they have to carry their own rations, might have limited access to food and consequently be forced to restrict their energy intake (Booth et al. 2003). This type of dietary practice has been shown to impair performance in a number of military relevant tasks (Nindl et al. 2002; Montain and Young 2003). Additionally, athletes and dieters might voluntarily restrict their energy intake to induce a reduction in body mass and/ or body fat. Among athletes, severe ER is particularly prevalent in weight categorised athletes (Horswill 1992) and jockeys (Moore et al. 2002), where it is used to help facilitate weight loss in the days leading up to weigh-in/ competition. Among those dieting for weight management or weight loss, intermittent severe ER for 1-2 days a week, with adequate energy intake on other days has been shown to lead to successful weight loss (Harvie et al. 2011).

Maintenance of exercise capabilities is an important consideration in all these settings to ensure completion of military exercise tasks in military personnel; effective adaptation to training programmes in athletes; and maximisation of energy deficits in dieters. Short periods of severe or complete ER have been shown to reduce exercise capacity (Loy et al. 1986; Nieman et al. 1987; Gleeson et al. 1988; Maughan and Gleeson 1988; Zinker et al. 1990) and performance (Oliver et al. 2007), and thus strategies to enhance endurance during severe ER are warranted. What accounts for this impaired endurance following severe or complete ER is not fully understood, but is likely related to reduced substrate (glycogen) availability. In the absence of exercise, 24-48 h severe ER is unlikely to cause muscle glycogen depletion (Dohm et al. 1986; Maughan and Williams 1981), but liver glycogen is likely to be depleted (Nilsson and Hultman 1973). Fatigue during exercise in the heat often occurs due to mechanisms unrelated to depletion of endogenous substrate (Nybo, 2010) and it is unknown whether severe ER impairs endurance in the heat. 
Severe ER, even with adequate water intake, results in a large reduction in body water stores (hypohydration), and particularly a reduction in plasma volume (James and Shirreffs 2013; Oliver et al. 2007; Consolazio et al. 1968). This hypohydration appears to be caused by the continued excretion of electrolytes in urine, despite little or no intake (James and Shirreffs 2013), and might be offset by electrolyte supplementation during severe ER (Consolazio et al. 1968a). Hypohydration reduces endurance capacity and performance (Cheuvront and Kenefick 2014), an effect that is exacerbated as environmental temperature increases (Kenefick et al. 2010). Therefore, the hypohydration, and particularly plasma volume reduction, that accompanies severe ER might negatively impact on exercise capacity (Cheuvront and Kenefick 2014), particularly if exercise is undertaken in a hot environment.

Manipulation of plasma volume by pre-exercise electrolyte ingestion has been shown to prolong exercise capacity in the heat (Sims et al. 2007; Hamouti et al. 2014). If the hypohydration and plasma volume reduction that accompanies severe ER is involved in fatigue during exercise, then preventing or attenuating this reduction might prolong exercise. Therefore, the aims of this study were to examine the effect of acute severe ER on exercise capacity in the heat, and to determine whether electrolyte supplementation during severe ER attenuates the reduction in plasma volume and prolongs exercise capacity. It was hypothesised that severe ER would reduce exercise capacity in the heat, and that electrolyte supplementation would attenuate this reduction.

\section{Methods}

\section{Subjects}

Nine healthy males (mean (SD) age 25 (4) y, body mass 76.98 (4.45) kg, height 1.76 (0.08) $\mathrm{m}, \dot{V} \mathrm{O}_{2}$ peak $56.3(6.7) \mathrm{ml} \cdot \mathrm{kg}^{-1} \cdot \mathrm{min}^{-1}$ ) volunteered for this study, which was approved by the University's Ethical Advisory Committee (Reference number R08P127). All subjects were physically active and participated in a variety of different sports, but were not trained cyclists or heat acclimated at the time of the study.

Experimental protocol 
Subjects completed a preliminary trial, a familiarisation trial and three experimental trials, which were completed in a randomised counterbalanced order. Experimental trials were conducted on the same day of the week and separated by at least 1 week. Trials were undertaken during the months of April, May, June, July and August in Loughborough, UK, with mean daily temperatures of 14.9 (3.6) ${ }^{\circ} \mathrm{C}$.

During the preliminary trial, $\dot{V} \mathrm{O}_{2}$ peak was determined using a discontinuous test on a cycle ergometer (Gould Corival 300, Groningen, Holland). After an initial 5 min stage at $100 \mathrm{~W}$, subjects completed 4 min stages at increasing workloads until volitional fatigue. Stages were separated by $\sim 5$ min rest. Heart rate and rating of perceived exertion (RPE) were recorded at the end of each stage, whilst expired air was collected into a Douglas bag for the final min of each stage. Oxygen and carbon dioxide content (Servomex 1400, Crawley, East Sussex, United Kingdom), volume (Harvard Dry Gas Meter, Harvard Apparatus Ltd, Kent, United Kingdom) and temperature (Edale digital thermometer) of each expired air sample was determined. $\dot{V} \mathrm{O}_{2}$ peak was defined as the highest $\dot{V} \mathrm{O}_{2}$ obtained and was used together with the relationship between $\dot{V} \mathrm{O}_{2}$ and workload to determine the work load required to elicit $60 \% \dot{V} \mathrm{O}_{2}$ peak during the exercise capacity tests. During the familiarisation trial, subjects were familiarised with the exercise capacity test, as well as blood and urine sampling procedures.

Each experimental trial consisted of $48 \mathrm{~h}$ dietary control and manipulation, before completing an exercise capacity test on a cycle ergometer. Subjects visited the laboratory in the morning at the same time of day (7-9 am) on 3 consecutive days (0 h, $24 \mathrm{~h}$ and $48 \mathrm{~h}$ ). On each of these visits, subjects arrived after a $10 \mathrm{~h}$ overnight fast and voided their bladder, before nude body mass was measured. A venous blood sample was then obtained by venepuncture of an antecubital vein. At $0 \mathrm{~h}$ and $24 \mathrm{~h}$, subjects were provided with their food and drink for the next $24 \mathrm{~h}$, instructions of when to consume each item, and $24 \mathrm{~h}$ urine collection equipment. At $48 \mathrm{~h}$, immediately after nude body mass measurement, subjects positioned a rectal thermistor (YSI 400 series, YSI Ltd., Farnborough, UK) $10 \mathrm{~cm}$ beyond the anal sphincter, for measurement of rectal temperature $\left(\mathrm{T}_{\text {rec }}\right.$ ). Skin thermistors (YSI 400 series) were then attached at 4 sites (chest, triceps, thigh and calf) and were used to 
determine weighted mean skin temperature $\left(T_{\text {sk }}\right)$ (Ramanathan 1964). A heart rate telemetry band (Polar Beat, Kempele, Finland) was positioned on the subject's chest. Resting core temperature, skin temperature and heart rate measurements, as well as perceived thermal comfort (TC) were taken after 15 min seated rest at room temperature (23.5 (1.3) ${ }^{\circ} \mathrm{C}, 44.6$ (8.2) \% relative humidity). The area of skin over the subject's right scapula was cleaned with distilled water and thoroughly dried using sterile gauze, before a small absorbent gauze patch (Tergaderm +Pad, 3M Healthcare, Loughborough, UK) was attached for the collection of sweat secreted during exercise. Subjects then entered a temperature (35.2 (0.2) ${ }^{\circ} \mathrm{C}$ ) and humidity (61.5 (3.6) \%) controlled environmental chamber (Weiss Gallenkamp, Loughborough, UK) and exercised at a workload intended to illicit $60 \% \dot{V} \mathrm{O}_{2}$ peak. Exercise continued until subjects could no longer maintain a pedal cadence of 60 revolutions per minute, despite verbal encouragement. One min expired air samples were collected every 15 min. RPE and TC were recorded every $10 \mathrm{~min}$, whilst core temperature, skin temperature and heart rate were recorded every $10 \mathrm{~min}$ and at the point of fatigue. After exercise, the absorbent gauze patch was removed and the sweat collected was aspirated using a syringe. After thoroughly towel drying, nude body mass was measured. The same investigator supervised all exercise trials.

\section{Dietary conditions}

Three different dietary conditions of varying energy and electrolyte content were applied during the experimental trials (Table 1). Subjects were provided with their food and drink for each $24 \mathrm{~h}$ during their morning visit to the laboratory ( $0 \mathrm{~h}$ and 24 h). During each $24 \mathrm{~h}$ period, subjects consumed a meal at $0 \mathrm{~h}, 4 \mathrm{~h}, 8 \mathrm{~h}$ and $12 \mathrm{~h}$ (i.e. 8am, 12pm, 4pm and 8pm for a subject starting at 8am), whilst they ingested a volume of drink equivalent to $5 \mathrm{ml} \cdot \mathrm{kg}^{-1}$ body mass at $0 \mathrm{~h}, 0-4 \mathrm{~h}, 4 \mathrm{~h}, 4-8 \mathrm{~h}, 8 \mathrm{~h}, 8-12$ h, $12 \mathrm{~h}$ and $14 \mathrm{~h}$. The drinks provided between meals were tap water, whilst drinks provided with meals contained a small amount of sugar-free blackcurrant squash. Daily energy requirements were estimated from subjects' resting energy expenditure (Mifflin et al. 1990) multiplied by a physical activity level of 1.5 . The diet provided to subjects was designed to contain a high proportion of carbohydrate (55-60\%) and consisted of jam sandwiches for breakfast $(0 \mathrm{~h})$, cheese sandwiches for lunch (4 h) and pasta for dinner $(12 \mathrm{~h})$, with other carbohydrate based snacks provided at $8 \mathrm{~h}$ and 
with all meals. During the control trial $(\mathrm{CON})$ subjects were provided with their estimated energy requirement, whilst during energy restricted trials (ER-E and ER-P) subjects were provided $\sim 33 \%$ of their estimated energy requirement. Sodium and potassium intake was also manipulated so that subjects consumed $2.2 \mathrm{mmol} \cdot \mathrm{kg}^{-1}$ body mass $\cdot \mathrm{d}^{-1}$ sodium and $0.8 \mathrm{mmol} \cdot \mathrm{kg}^{-1}$ body mass $\cdot \mathrm{d}^{-1}$ potassium during CON and ER-E. This intake of electrolytes was provided in foods consumed during each trial, with additional sodium chloride in capsules consumed at $0 \mathrm{~h}, 4 \mathrm{~h}, 8 \mathrm{~h}$ and $12 \mathrm{~h}$ and additional potassium chloride added to drinks and capsules consumed at 0 h, 4 h, $8 \mathrm{~h}$ and 12 h. During ER-P, placebo capsules containing a small amount of maltodextrin were provided with meals. To determine the electrolyte content of each food item used in the study, a sample of each food was weighed and homogenised with a known amount of distilled water, with a sample of each homogenate analysed for sodium and potassium content before the start of the study. ER trials were administered in a single blind manner so that subjects were unaware of which trial they were undertaking. At $24 \mathrm{~h}$ and $48 \mathrm{~h}$ subjects confirmed their compliance with the dietary intervention verbally upon arrival to the laboratory.

\section{Analytical methods}

All blood samples were taken after 15 min upright seated rest. One ml of blood was mixed with $\mathrm{K}_{2}$ EDTA $\left(1.75 \mathrm{mg} \cdot \mathrm{ml}^{-1}\right)$ and analysed for haematocrit by microcentrifugation, haemoglobin concentration by the cyanmethaemoglobin method and, after 10:1 dilution in perchloric acid, glucose concentration by the GOD-PAP method. One ml of each blood sample was mixed with lithium heparin in a pre-chilled tube and used for the determination of blood $\mathrm{pH}$ (ABL5 blood gas analyser, Radiometer Ltd, Crawley, UK). The remaining blood was allowed to clot and serum was separated by centrifugation. Serum and urine samples were analyzed for osmolality by freezing point depression (Gonotec Osmomat 030 Cryoscopic Osmometer; Gonotec, Berlin, Germany) and sodium and potassium concentration by flame photometry (Corning Clinical Flame Photometry 410C; Corning Ltd., Halstead, Essex, UK). Sweat samples were analysed for sodium and potassium concentration by flame photometry. Urine was also analysed for creatinine concentration by a modification of the Jaffe reaction (Owen et al. 1954). 


\section{Statistical analysis and calculations}

All data were checked for normality of distribution using a Shapiro-Wilk test. Data sets containing two factors were analysed using two-way repeated measures ANOVA and if the assumption of sphericity was violated, the degrees of freedom were corrected using the Greenhouse-Geisser estimate. Data sets containing one factor were analysed using one-way repeated measures ANOVA or Friedman's ANOVA, as appropriate. Post-hoc Bonferroni-adjusted t-tests or Bonferroni-adjusted Wilcoxon signed rank tests were used where appropriate. Normally distributed data are presented as mean (SD), whilst non-normally distributed data are presented as median (range). Data were accepted as being significantly different when $P \leq 0.05$.

Haemoglobin and haematocrit values were used to estimate changes in plasma volume, relative to pre-exercise (Dill and Costill 1974). Change in body mass during exercise was used to determine sweat loss.

\section{Results}

Pre-trial measurements

Pre-trial body mass (CON: 76.47 (3.76) kg; ER-E: 76.53 (4.31) kg; ER-P: 76.67 (4.29) kg; $P=0.855)$ and serum osmolality ( $P=0.342$; Table 3a) were not different between trials indicating subjects started each trial in a similar state of hydration. There was no difference between trials for mean $24 \mathrm{~h}$ urine creatinine excretion $(P=0.250)$ and over all trials it was $0.23(0.03) \mathrm{mmol} \cdot \mathrm{kg}$ body mass ${ }^{-1} \cdot 24 \mathrm{~h}^{-1}$, which is indicative of a complete 24 h urine collection (Bingham and Cummings, 1985).

\section{Body mass, urine output and electrolyte balance}

There was an interaction effect $(P<0.001)$ for body mass change over the $48 \mathrm{~h}$ dietary intervention period (Figure 1), with all trials resulting in a net loss of body mass, equating to $0.54(0.91) \%,-1.89(0.72) \%$ and $-2.83(0.56) \%$ of initial body mass during the CON, ER-E and ER-P trials, respectively. Body mass loss over the $48 \mathrm{~h}$ was greater during ER-E and ER-P than CON, as well as greater during ER-P than ER-E $(P<0.01)$.

Urine output (Table 2a) over the $48 \mathrm{~h}$ was greater during ER-P compared to CON $(P<0.01)$ and ER-E $(P<0.05)$. Urine sodium excretion (Table $2 \mathrm{~b})$ was greater during 
CON and ER-E compared to ER-P $(P<0.01)$, but the greater sodium intake during CON and ER-E meant that sodium balance (Table 2d) over the $48 \mathrm{~h}$ was more positive during CON and ER-E than during ER-P $(P<0.05)$. Potassium excretion (Table 2c) over the $48 \mathrm{~h}$ was lower for ER-P compared to CON and ER-E $(P<0.01)$, but potassium balance (Table 2e) was not different between trials $(P=0.250)$. For morning urine osmolality there was a time effect $(P<0.05)$, but no trial $(P=0.311)$ or interaction effect $(P=0.855)$ and over all trials, urine osmolality decreased from $\sim 730$ mosmol $\cdot \mathrm{kg}^{-1}$ at $0 \mathrm{~h}$ to $\sim 570 \mathrm{mosmol} \cdot \mathrm{kg}^{-1}$ at $24 \mathrm{~h}$ and $\sim 580 \mathrm{mosmol} \cdot \mathrm{kg}^{-1}$ at $48 \mathrm{~h}$.

\section{Blood markers}

There were no time, trial or interaction effects $(P>0.05)$ for serum osmolality (Table 3a), serum sodium concentration (Table 3b), serum potassium concentration (Table 3c), blood glucose concentration (Table 3d) or blood pH (data not shown). There was an interaction effect $(P<0.001)$ for change in plasma volume (Figure 2$)$, with a reduction in plasma volume during ER-P $(P<0.001)$, but not CON or ER-E. This meant that plasma volume was lower at $24 \mathrm{~h}$ and $48 \mathrm{~h}$ during ER-P compared to both CON and ER-E $(P<0.001)$.

\section{Exercise capacity test}

Exercise capacity (Table 4) was greater during CON and ER-E compared to ER-P $(P<0.01)$, but was not different between trials CON and ER-E $(P=0.237)$. There was no trial order effect over the three trials ( $P=0.735$ ), with mean exercise times of 63.8 (17.3) $\mathrm{min}, 67.8$ (18.2) $\mathrm{min}$ and 65.4 (13.2) min, during the first, second and third trials, respectively.

There was no time ( $P=0.541)$, trial $(P=0.334)$ or interaction effect $(P=0.584)$ for RER, and over all trials RER was 0.94 (0.04). Consequently, there was no time, trial or interaction effect for carbohydrate or fat oxidation ( $P>0.504)$, with mean values over all trials of $2.78(0.51) \mathrm{g} \cdot \mathrm{min}^{-1}$ and $0.28(0.19) \mathrm{g} \cdot \mathrm{min}^{-1}$, respectively. Sweat rate ( $P=0.944$ ), sweat sodium concentration $(P=0.384)$ and sweat potassium concentration $(P=0.160)$ were not different between trials, and over all trials were $1.35(0.19) \mathrm{l} \cdot \mathrm{h}^{-1}$, 56 (16) $\mathrm{mmol} \cdot \mathrm{l}^{-1}$ and $5.5(0.9) \mathrm{mmol} \cdot \mathrm{l}^{-1}$, respectively. 
There was a main effect of trial $(P<0.001)$, and a tendency for an interaction effect $(P=0.084)$ for heart rate (Table $5 a)$. Heart rate was greater during ER-P compared to ER-E at rest $(P<0.01)$, and compared to both CON and ER-E at $10 \mathrm{~min}, 20 \mathrm{~min}$ and $30 \mathrm{~min}$ of exercise $(P<0.01)$. Whilst there were main effects of time for both rectal temperature (Table $5 b$ ) and weighted mean skin temperature (Table $5 \mathrm{c}$ ), there were no

trial $(P=0.135 ; \quad P=0.468$, respectively) or interaction $(P=0.070 ; \quad P=0.323$, respectively) effects. There was a main effect of trial $(P<0.001)$ for RPE, but no interaction effect $(P<0.552)$ and compared to CON, RPE was greater at $10 \mathrm{~min}$ and 20 min during ER-E and ER-P, as well as at 30 min during ER-P. There were no trial $(P=0.173)$ or interaction $(P=0.496)$ effect for thermal comfort (Table 3e).

\section{Discussion}

The aim of this study was to determine the effect of severe ER on exercise capacity in the heat, as well as determine the impact of sodium chloride and potassium chloride supplementation during severe ER on fluid balance and exercise capacity. The main finding was that $48 \mathrm{~h}$ severe ER reduced exercise capacity in the heat compared to an adequate energy control trial, and that supplementation of sodium chloride and potassium chloride during ER attenuated the reduction in exercise capacity.

Severe ER results in a large reduction in body mass that appears to be greatest over the initial 2 days of ER (Consolazio et al. 1968a) and is accompanied by a large reduction in plasma volume during this time (Consolazio et al. 1968a; Oliver et al. 2007; James and Shirreffs 2013). As observed here, and previously (James and Shirreffs 2013) the excretion of the electrolytes sodium and potassium in urine continues during severe ER, despite a greatly reduced intake. Although large over the first 2 days of severe ER, the body mass loss becomes smaller and more consistent thereafter (Consolazio et al., 1968a). Similarly, sodium excretion in urine is large over the initial stages of ER and falls to minimal levels by 2-4 days of severe ER (Consolazio et al. 1968b). It is likely that the larger reduction in body mass observed during the first few days of severe ER is mostly explained by a rapid reduction in body water stores (Consolazio et al. 1968a), whilst the smaller, more consistent losses thereafter are likely reflective of a loss of body fat and muscle. The present results demonstrate that whilst supplementing with sodium chloride and potassium chloride during severe ER increased sodium and potassium losses in urine, the increased loss 
was not sufficient to account for the additional intake, at least for sodium. Therefore a more positive electrolyte balance was achieved. Electrolyte supplementation during severe ER attenuated the body mass loss and prevented the loss of plasma volume observed during severe ER.

These results suggest that water and electrolyte imbalances contribute to the large loss of body mass observed during severe ER. This is supported by the data for urine output, which over the $48 \mathrm{~h}$ intervention was increased during ER-P, but not ER-E, compared to CON. Therefore, severe ER accompanied by severe electrolyte restriction leads to increased urine production and the loss of water stores (i.e. plasma volume), even with adequate water intake. The effect of sodium intake on fluid balance is well documented, and the retention of fluid ingested when hypohydrated is directly related to the sodium concentration of the drink (Shirreffs and Maughan 1998). In contrast, potassium addition to drinks ingested after either exercise-induced hypohydration (Shirreffs et al. 2007) or fluid and ER (James and Shirreffs 2015) does not appear to increase drink retention. Given that sodium, but not potassium balance was significantly greater during CON and ER-E than ER-P, it seems likely that sodium played a more important role in the reduction in urine output observed. If sodium intake is maintained, electrolyte balance is also maintained and the diuresis associated with severe ER is attenuated. Sodium and potassium are the main cations in the extracellular and intracellular spaces, respectively, and are responsible for the regulation of the volume of fluid compartments. Whilst serum osmolality and electrolyte concentrations were not different between trials, it is likely that electrolyte supplementation during ER attenuated the transient decrease in serum osmolality that occurs after drinking and thus reduced urine output (Nose et al. 1988).

Previous research has reported a reduction in exercise capacity (Loy et al., 1986; Nieman et al. 1987; Gleeson et al. 1988; Zinker et al. 1990) and performance (Oliver et al. 2007) following 24-48 h severe ER. These reductions in exercise capacity have been observed during running and cycling, and over a range of exercise intensities (50-100\% $\dot{V} \mathrm{O}_{2} \max$ ). The reason for a reduction in endurance following short term periods of severe or complete ER is not fully understood, but is likely to be multifactorial in nature. Severe ER results in reductions in liver glycogen (Nilsson 
and Hultman 1973) and alterations in substrate utilisation at rest and during exercise (Dohm et al. 1986; Nieman et al. 1987; Knapik et al. 1988; Maughan and Gleeson 1988), as well as an increase in heart rate (Dohm et al. 1986; Knapik et al. 1987; Nieman et al. 1987) and perceived exertion (Nieman et al. 1987) during exercise.

All previous studies looking at ER and endurance exercise have examined exercise in a temperate environment. Thus the present study extends these previous findings by demonstrating that exercise capacity is also reduced in a hot environment. In temperate environments fatigue during prolonged endurance exercise can mainly be attributed to depletion of muscle and liver glycogen (Coyle 2004). However, in the heat, fatigue often occurs before glycogen stores have become sufficiently depleted to limit endurance (Coyle 2004). The majority of previous studies have examined the effects of complete ER, whilst in the present study, subjects consumed 3693 (219) $\mathrm{kJ} \cdot \mathrm{d}^{-1}$ and $129(13) \mathrm{g} \cdot \mathrm{d}^{-1}$ carbohydrate. During the $48 \mathrm{~h}$ restriction period, subjects performed no exercise and thus carbohydrate consumed was likely sufficient to meet subjects' obligate requirement (Maughan et al. 2010). Therefore, the ER imposed in the present study was unlikely to influence muscle glycogen (Dohm et al. 1986; Maughan and Williams 1981) and the provision of some carbohydrate during ER would have reduced the impact on liver glycogen compared to complete ER (Nilsson and Hultman 1973). This hypothesis is supported by the finding that there was no difference in carbohydrate or fat oxidation during exercise.

It is well known that the effects of hypohydration on exercise performance are more profound in hot than temperate environments (Kenefick et al. 2010). The present study implicates the hypohydration and reduced plasma volume observed during severe ER with fatigue during exercise, at least in the heat. It remains to be seen, however, if supplemention of electrolytes during ER can maintain exercise capacity in temperate/ cool environments. Ingestion of sodium in the immediate pre-exercise period has been shown to increase exercise capacity (Sims et al. 2007) and exercise performance (Hamouti et al. 2014) in the heat. In these studies, pre-exercise sodium ingestion increased plasma volume (Sims et al., 2007; Hamouti et al. 2014) relative to a low/ no sodium control trial. Sims et al. (2007) reported that heart rate during exercise was lower following pre-exercise sodium ingestion, whilst Hamouti et al. (2014) reported greater stroke volume and cardiac output following pre-exercise 
sodium ingestion. In the present study, ER resulted in an increased heart rate during exercise compared to the control trial, an effect that was prevented by electrolyte supplementation during ER. Therefore it seems likely that the most plausible explanation for the reduction in exercise capacity with ER in the present study might be related to an increased cardiovascular strain brought about by the reduced plasma volume during ER (Nybo 2010). In the present study, the severe ER induced an isotonic hypovolaemia, which induces a larger relative plasma volume reduction per unit body water lost compared to hypertonic hypovolaemia (Cheuvront and Kennefick 2014). As the reduced plasma volume and increased cardiovascular strain observed during hypohydration might be responsible for the impairment of endurance performance/ capacity, the larger relative loss of plasma volume with severe ER might have a larger effect on endurance.

The maintenance of exercise capacity during periods of ER might be of importance in a number of settings. Intermittent, severe ER creates a large energy deficit and from a weight loss perspective has been shown to be comparable to moderate daily ER (Harvie et al. 2011). This type of dietary strategy might therefore offer a method of weight loss that doesn't require daily adherence to a diet. A recent meta-analysis suggested that for long term sustainable weight loss, interventions that combine exercise regimens with dietary restriction offer the best chance of success (Franz et al. 2007). Thus maintenance of exercise capabilities in this population might be of great importance. Similarly, military personal might encounter periods or severe ER during field exercise or sustained operations (Nindle et al. 2002), whilst athletes might voluntarily restrict their energy intake to induce body mass/ fat mass loss (Moore et al. 2002). As such, supplementation of sodium chloride and potassium chloride during severe ER might enhance energy expenditure through exercise during weight management programmes, ensure adequate completion of military related tasks or ensure appropriate training volume and adaptation in athletes.

Although there was no statistically significant difference for exercise capacity between CON and ER-E, subjects exercised for $\sim 6.5$ min longer during CON than ER-E, with 6 of the 9 subjects exercising longer during CON. Using the data for these trials, a $\beta$ of 0.8 , it was estimated that 22 subjects would be required to reject the null hypothesis in the present study design. Therefore care should be taken with the 
interpretation of the present results, which suggest that electrolyte supplementation attenuates, but does not prevent the reduction in exercise capacity induced by severe ER. Exercise capacity tests have generally been shown to be less reliable and less sensitive than time trial type exercise protocols (Currell and Jeukendrup 2008). Exercise capacity tests similar to that used in the present study have been shown to have a coefficient of variation of $5-26 \%$, compared to $<5 \%$ for time trial type protocols (Currell and Jeukendrup 2008). Therefore, use of a time trial in future studies might help elucidate whether there is a difference between CON and ER-E.

In conclusion the present study demonstrates that the supplementation of sodium chloride and potassium chloride during a $48 \mathrm{~h}$ period of severe ER (33\% energy requirement) prevented the reduction in plasma volume and negative sodium balance that occurred without electrolyte supplementation. During severe ER, electrolyte supplementation also resulted in a lower heart rate during exercise and increased exercise capacity compared to severe ER alone.

\section{Acknowledgements}

The authors would like to thank Dr Phillip Watson for his assistance with blood sampling during this study. 


\section{References}

Bingham SA and Cummings JH (1985) The use of creatinine output as a check on the completeness of 24-hour urine collections. Hum Nutr Clin Nutr 39:343-353.

Booth CK, Coad RA, Forbes-Ewan CH, Thompson GF and Niro PJ (2003) The

physiological and psychological effects of combat ration feeding during a 12-day training exercise in the tropics. Mil Med 168:63-70.

Cheuvront SN and Kenefick RW (2014) Dehydration: physiology, assessment and performance effects. Compr Physiol 4:257-285.

Consolazio CF, Matoush LO, Johnson HL, Krzywicki HJ, Isaac GJ and Witt NF (1968a) Metabolic aspects of calorie restriction: hypohydration effects on body weight and blood parameters. Am J Clin Nutr 21:793-802.

Consolazio CF, Matoush LO, Johnson HL, Krzywicki HJ, Isaac GJ and Witt NF (1968b) Metabolic aspects of calorie restriction: nitrogen and mineral balances and vitamin excretion. Am J Clin Nutr 21:803-812.

Coyle EF (2004) Fluid and Fuel intake during exercise. J Sports Sci 22:39-55.

Currell K and Jeukendrup AE (2008) Validity, reliability and sensitivity of measures of sporting performance. Sports Med 38:297-316.

Dohm GL, Beeker RT, Israel RG and Tapscott EB (1986) Metabolic responses to exercise after fasting. J Appl Physiol 61:1363-1368.

Dohm GL, Tapscott EB, Bakarat HA and Kasperek GJ (1983) Influence of fasting on glycogen depletion in rats during exercise. J Appl Physiol 55:830-833.

Dill DB and Costill DL (1974) Calculation of percentage changes in blood, plasma, and red cells in dehydration. J Appl Physiol 37:247-248 
Franz MJ, VanWormer JJ, Crain AL, Boucher JL, Histon T, Caplan W, Bowman JD and Pronk NP (2007) Weight-loss outcomes: a systematic review and meta-analysis of weight-loss clinical trials with a minimum 1-year follow-up. J Am Diet Assoc 107:1755-1767.

Gleeson M, Greenhaff PL and Maughan RJ (1988) Influence of a 24 h fast on high intensity cycle exercise performance in man. Eur J Appl Physiol 57:653-659.

Hamouti N, Fernández-Elías VE, Ortega JF and Mora-Rodriguez R (2014) Ingestion of sodium plus water improves cardiovascular function and performance during dehydrating clycling in the heat. Scand J Med Sci Sports 24:507-518.

Harvie MN, Pegington M, Mattson MP, Frystyk J, Dillon B, Evans G, Cuzick J, Jebb SA, Martin B, Cutler RG, Son TG, Maudsley S, Carlson OD, Egan JM, Flyvbjerg A and Howell A (2011) The effects of intermittent or continuous energy restriction on weight loss and metabolic disease risk markers: a randomized trial in young overweight women. Int J Obes 35:714-727.

Horswill CA (1992) Applied physiology of amateur wrestling. Sports Med 14:114143.

Knapik JJ, Jones BH, Meredith C and Evans WJ (1987) Influence of a 3.5 day fast on physical performance. Eur J Appl Physiol 56:428-432.

James LJ and Shirreffs SM (2013) Fluid and electrolyte balance during 24-hour fluid and/or energy restriction. Int J Sport Nutr Exerc Metab 23:545-553.

James LJ and Shirreffs SM (2015) Effect of electrolyte addition to rehydration drinks consumed after severe fluid and energy restriction. J Strength Cond Res 29:521-527.

Kenefick RW, Cheuvront SN, Palombo LJ, Ely BR, Sawka MN (2010) Skin temperature modifies the impact of hypohydration on aerobic performance. J Appl Physiol 109:79-86. 
Loy SF, Conlee RK, Winder WW, Nelson AG, Arnall DA and Fisher AG (1986) Effects of 24-hour fast on cycling endurance time at two different intensities. J Appl Physiol 61:654-659.

Maughan RJ, Fallah J and Coyle EF (2010) The effects of fasting on metabolism and performance. Br J Sports Med 44:490-494.

Maughan RJ and Gleeson M (1988) Influence of a 36 h fast followed by refeeding with glucose, glycerol or placebo on metabolism and performance during prolonged exercise in man. Eur J Appl Physiol 57:570-576.

Maughan RJ and Williams C (1981) Differential effects of fasting on skeletal muscle glycogen content in man and on skeletal and cardiac glycogen muscle content in rats. Proc Nutr Soc 40:85A.

Mifflin MD, St Jeor ST, Hill LA, Scott BJ, Daugherty SA and Koh YO. (1990) A new predictive equation for resting energy expenditure in healthy individuals. Am J Clin Nutr 51:241-247.

Montain SJ and Young AJ (2003) Diet and physical performance. Appetite 40:255267.

Moore JM, Timperio AF, Crawford DA, Burns CM and Cameron-Smith D (2002) Weight management and weight loss strategies of professional jockeys. Int J Sport Nutr Exerc Metab 12:1-13.

Nieman DC, Carlson KA, Brandstater ME, Naegele RT and Blankenship JW (1987) Running endurance in 27-h-fasted humans. J Appl Physiol 63:2502-2509.

Nilsson LH and Hultman E (1973) Liver glycogen in man- the effect of total starvation or a carbohydrate poor diet followed by carbohydrate refeeding. Scand J Clin Lab Invest 32:325-330. 
Nindl BC, Leone CD, Tharion WJ, Johnson RF, Castellani JW, Patton JF and Montain SJ (2002) Physical performance responses during $72 \mathrm{~h}$ of military operational stress. Med Sci Sports Exerc 34:1814-1822.

Nose H, Mack GW, Shi XR and Nadel ER (1988) Role of osmolality and plasma volume during rehydration in humans. J Appl Physiol 65:325-331.

Nybo L (2010) Cycling in the heat: performance perspectives and cerebral challenges. Scand J Med Sci Sports 20:71-79.

Oliver SJ, Laing SJ, Wilson S, Bilson JLJ and Walsh N (2007) Endurance running performance after $48 \mathrm{~h}$ of restricted fluid and/ or energy intake. Med Sci Sports Exerc 39:316-312.

Owen JA, Iggo B, Scandrett FJ, and Stewart CP (1954) The determination of creatinine in plasma or serum and urine: a critical examination. Biochem J 58:426437.

Ramanathan NL (1964) A new weighting system for surface temperature of the human body. J Appl Physiol 19:531-533.

Sawka MN, Burke LM, Eichner ER, Maughan RJ, Montain SJ and Stachenfeld NS (2007) Exercise and fluid replacement. Med Sci Sports Exerc 39:377-390.

Shirreffs SM and Maughan RJ (1998) Volume repletion after exercise-induced volume depletion in humans: replacement of water and sodium losses. Am J Phys 274:F868-F875.

Shirreffs SM, Aragon-Vargas LF, Keil M, Love TD and Phillips S (2007) Rehydration after exercise in the heat: a comparison of 4 commonly used drinks. Int J Sport Nutr Exerc Metab 17:244-258. 
Sims ST, Rehrer NJ, Bell ML and Cotter JD (2007) Preexercise sodium loading aids fluid balance and endurance for women exercising in the heat. J Appl Physiol 103:534-541.

Zinker BA, Britz K and Brooks GA (1990) Effects of a 36-hour fast on human endurance and substrate utilisation. J Appl Physiol 69:1849-1855. 
Table 1. $24 \mathrm{~h}$ dietary intake during the $48 \mathrm{~h}$ dietary intervention period. Values are mean (SD).

\begin{tabular}{llll}
\hline & CON & ER-E & ER-P \\
\hline Energy (kJ) & $11258(673)$ & $3726(206)$ & $3721(203)$ \\
Protein (g) & $68(2)$ & $21(1)$ & $21(1)$ \\
Carbohydrate (g) & $375(25)$ & $130(12)$ & $130(13)$ \\
Fat (g) & $98(8)$ & $31(2)$ & $31(2)$ \\
Fibre (g) & $13(2)$ & $4(1)$ & $4(1)$ \\
Water (ml) & $3070(171)$ & $3085(164)$ & $3085(164)$ \\
Sodium (mmol) & $171(9)$ & $173(11)$ & $17(1)$ \\
Potassium (mmol) & $62(6)$ & $61(7)$ & $12(1)$ \\
\hline
\end{tabular}


Table 2. a) Urine volume (ml); b) urine sodium excretion (mmol); c) urine potassium excretion (mmol); d) sodium balance (mmol); and e) potassium balance (mmol) during the $48 \mathrm{~h}$ dietary intervention period. Values are mean (SD). * Significantly different from 0 -24 h. $\dagger$ Significantly different from CON. $\ddagger$ Significantly different from ER-E.

\begin{tabular}{|c|c|c|c|}
\hline & $0-24 \mathrm{~h}$ & $24-48 \mathrm{~h}$ & $0-48 \mathrm{~h}$ \\
\hline \multicolumn{4}{|c|}{ a) Urine volume (l) } \\
\hline $\mathrm{CON}$ & 2052 (657) & $2162(370)$ & $4214(975)$ \\
\hline ER-E & $2488(245)$ & $2320(298)^{*}$ & $4808(471)$ \\
\hline ER-P & $3103(402) \dagger$ & $2724(349) \dagger$ & $5828(242) \dagger+$ \\
\hline \multicolumn{4}{|c|}{ b) Urine sodium excretion (mmol) } \\
\hline $\mathrm{CON}$ & $156(49)$ & $166(24)$ & $323(51)$ \\
\hline ER-E & $197(33)$ & $169(34)$ & $366(50)$ \\
\hline ER-P & $112(44) \ddagger$ & $73(47) * \dagger \ddagger$ & $185(82) \dagger \ddagger$ \\
\hline \multicolumn{4}{|c|}{ c) Urine potassium excretion (mmol) } \\
\hline $\mathrm{CON}$ & $96(26)$ & $80(16)^{*}$ & $176(38)$ \\
\hline ER-E & $98(28)$ & $84(22)$ & $181(45)$ \\
\hline ER-P & $57(17) \dagger+$ & $52(21) \ddagger$ & $109(35) \dagger \ddagger$ \\
\hline \multicolumn{4}{|c|}{ d) Sodium balance (mmol) } \\
\hline $\mathrm{CON}$ & $15(54)$ & $3(30)$ & $19(64)$ \\
\hline ER-E & $-24(39)$ & $3(37)$ & $-21(61)$ \\
\hline ER-P & $-94(44) \dagger \ddagger$ & $-56(46)^{* \dagger \ddagger}$ & $-150(81) \dagger+$ \\
\hline \multicolumn{4}{|c|}{ e) Potassium balance (mmol) } \\
\hline $\mathrm{CON}$ & $-34(23)$ & $-18(15)^{*}$ & $-52(33)$ \\
\hline ER-E & $-36(32)$ & $-22(26)$ & $-56(54)$ \\
\hline ER-P & $-45(17)$ & $-39(21)$ & $-84(35)$ \\
\hline
\end{tabular}


Table 3. a) serum osmolality (mosmol $\left.\cdot \mathrm{kg}^{-1}\right)$; b) serum sodium concentration (mmol $\cdot \mathrm{l}^{-}$ $\left.{ }^{1}\right)$; c) serum potassium concentration $\left(\mathrm{mmol} \cdot \mathrm{l}^{-1}\right)$; d) blood glucose concentration $\left(\mathrm{mmol} \cdot \mathrm{l}^{-1}\right)$; during the $48 \mathrm{~h}$ dietary intervention period. Values are mean (SD).

\begin{tabular}{|c|c|c|c|}
\hline & $0 \mathrm{~h}$ & $24 \mathrm{~h}$ & $48 \mathrm{~h}$ \\
\hline \multicolumn{4}{|c|}{ a) Serum osmolality $\left(\mathrm{mosmol} \cdot \mathrm{kg}^{-1} \mathrm{H}_{2} \mathrm{O}\right)$} \\
\hline $\mathrm{CON}$ & $287(5)$ & $286(4)$ & $286(6)$ \\
\hline ER-E & $286(3)$ & $284(4)$ & $285(2)$ \\
\hline ER-P & $286(4)$ & $284(4)$ & $284(4)$ \\
\hline \multicolumn{4}{|c|}{ b) Serum sodium concentration $\left(\mathrm{mmol} \cdot \mathrm{l}^{-1}\right)$} \\
\hline $\mathrm{CON}$ & $142(3)$ & $143(1)$ & $142(2)$ \\
\hline ER-E & $143(2)$ & $142(2)$ & $143(3)$ \\
\hline ER-P & $142(2)$ & $143(2)$ & $143(1)$ \\
\hline \multicolumn{4}{|c|}{ c) Serum potassium concentration $\left(\mathrm{mmol} \cdot \mathrm{l}^{-1}\right)$} \\
\hline $\mathrm{CON}$ & $4.4(0.3)$ & $4.6(0.3)$ & $4.6(0.3)$ \\
\hline ER-E & $4.5(0.2)$ & $4.5(0.4)$ & $4.5(0.3)$ \\
\hline ER-P & $4.6(0.4)$ & $4.8(0.6)$ & $4.6(0.3)$ \\
\hline \multicolumn{4}{|c|}{ d) Blood glucose concentration $\left(\mathrm{mmol} \cdot 1^{-1}\right)$} \\
\hline $\mathrm{CON}$ & $4.62(0.45)$ & $4.73(0.40)$ & $4.80(0.29)$ \\
\hline ER-E & $4.70(0.34)$ & $4.86(0.44)$ & $4.52(0.39)$ \\
\hline ER-P & $4.43(0.34)$ & $4.56(0.51)$ & $4.62(0.37)$ \\
\hline
\end{tabular}


Table 4. Exercise capacity time (min) during trials. Individual times and group mean (SD) presented. † Significantly different from CON. $\ddagger$ Significantly different from ER-E.

\begin{tabular}{llll}
\hline & CON & ER-E & ER-P \\
\hline 1 & 78.37 & 84.12 & 76.00 \\
2 & 68.48 & 58.80 & 50.12 \\
3 & 90.98 & 85.38 & 73.27 \\
4 & 85.68 & 89.87 & 68.62 \\
5 & 71.67 & 51.25 & 45.25 \\
6 & 80.00 & 70.35 & 52.77 \\
7 & 60.68 & 65.25 & 53.37 \\
8 & 47.00 & 37.85 & 38.37 \\
9 & 79.32 & 60.40 & 50.53 \\
\hline Mean & 73.58 & 67.03 & $56.48 \dagger \ddagger$ \\
SD & 13.46 & 17.24 & 13.06 \\
\hline
\end{tabular}


Table 5. a) heart rate (beats $\left.\cdot \mathrm{min}^{-1}\right)$; b) rectal temperature $\left({ }^{\circ} \mathrm{C}\right)$; c) weighted mean skin temperature $\left({ }^{\circ} \mathrm{C}\right)$; d) rating of perceived exertion; and e) thermal comfort before and during the exercise capacity test. Values are mean (SD). † Significantly different from CON. $\ddagger$ Significantly different from ER-E. For all variables, all values after baseline values were significantly increased from baseline.

\begin{tabular}{llllll}
\hline & 0 min & 10 min & 20 min & 30 min & Exhaustion \\
\hline \multicolumn{2}{l}{ a) Heart rate $\left(\right.$ beats $\cdot \mathrm{min}^{-1}$ ) } & & & & \\
CON & $66(7)$ & $140(11)$ & $150(10)$ & $155(12)$ & $173(11)$ \\
ER-E & $62(8)$ & $141(11)$ & $151(11)$ & $157(11)$ & $174(10)$ \\
ER-P & $70(9) \ddagger$ & $151(10) \dagger \ddagger$ & $158(11) \dagger \ddagger$ & $165(11) \dagger \ddagger$ & $176(9)$
\end{tabular}

b) Rectal temperature $\left({ }^{\circ} \mathrm{C}\right)$

$\begin{array}{llllll}\text { CON } & 37.1(0.2) & 37.3(0.1) & 37.7(0.1) & 38.0(0.2) & 39.0(0.4) \\ \text { ER-E } & 37.1(0.2) & 37.3(0.2) & 37.7(0.1) & 38.0(0.1) & 38.9(0.4) \\ \text { ER-P } & 37.2(0.2) & 37.4(0.2) & 37.8(0.1) & 38.0(0.1) & 39.0(0.4)\end{array}$

c) Weighted mean skin temperature $\left({ }^{\circ} \mathrm{C}\right)$

$\begin{array}{llllll}\text { CON } & 32.6(0.6) & 35.6(0.4) & 36.0(0.3) & 36.2(0.3) & 36.6(0.5) \\ \text { ER-E } & 32.6(0.8) & 35.5(0.4) & 35.9(0.3) & 36.0(0.3) & 36.3(0.4) \\ \text { ER-P } & 32.8(0.8) & 35.5(0.5) & 35.9(0.5) & 36.0(0.5) & 36.4(0.6)\end{array}$

d) Rating of perceived exertion

$\begin{array}{llllll}\text { CON } & - & 11.2(1.9) & 12.7(2.1) & 14.0(2.2) & - \\ \text { ER-E } & - & 12.9(1.8) \dagger & 14.3(1.6) \dagger & 15.6(1.6) \dagger & - \\ \text { ER-P } & - & 12.4(1.7) \dagger & 13.8(1.7) \dagger & 15.7(1.7) & -\end{array}$

e) Thermal comfort

\begin{tabular}{llllll} 
CON & $1.6(0.5)$ & $3.0(0.7)$ & $4.2(1.3)$ & $4.9(1.5)$ & - \\
ER-E & $1.8(0.8)$ & $3.6(0.9)$ & $4.8(1.1)$ & $5.6(1.4)$ & - \\
ER-P & $1.2(1.2)$ & $3.2(1.2)$ & $4.3(1.1)$ & $5.4(1.7)$ & - \\
\hline
\end{tabular}


Figure 1. Change in body mass relative to $0 \mathrm{~h}(\mathrm{~kg})$ during the $48 \mathrm{~h}$ dietary intervention period. Points are mean values. Error bars are SD. * Significantly different from 0 h. $\dagger$ Significantly different from CON. $\ddagger$ Significantly different from ER-E.

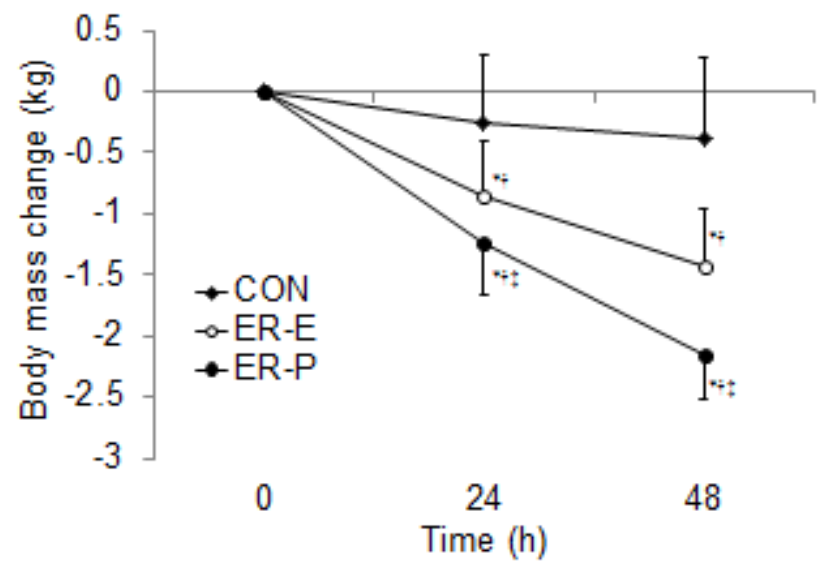

Figure 1 
Figure 2. Change in plasma volume relative to $0 \mathrm{~h}$ (\%) during the $48 \mathrm{~h}$ dietary intervention period. Points are mean values. Error bars are SD. * Significantly different from 0 h. $†$ Significantly different from CON. $\ddagger$ Significantly different from ER-E.

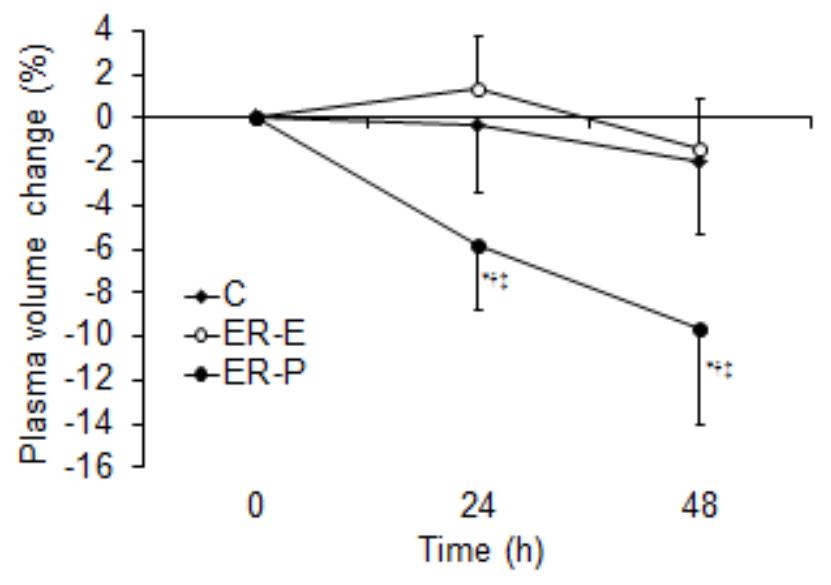

Figure 2 